\title{
Shifting perspectives - How the masks we wear can facilitate and inhibit channels of communication in the social-environmental policy context
}

Ruth E. Brennan, Branka Valcic ${ }^{1}$

Centre for Sustainable Coasts, Scottish Association for Marine Science, Scottish Marine Institute, Oban, Argyll PA37 1QA, Scotland, UK

${ }^{1}$ The order of authors was determined randomly by tossing a coin as the respective contributions of the authors to this paper are equal.

\section{Abstract}

Everyone shares the human condition, but we play it out in different ways. As scientists, we play a role when we work, speak and write as scientists. A recently completed EU-funded multidisciplinary project on integrating science and policy in the context of coastal management (SPICOSA) illustrates how divorcing this role of scientist from the underlying context of a human being with values and opinions gives rise to the illusion that science can remain detached from the human messiness of the social-environmental policy context. An ongoing social-

environmental conflict in Barra in the Outer Hebrides, Scotland illustrates different perspectives on marine conservation held by different roles (policy makers and local community). Our roles position us on the social grid and allow us to function in society. We speculate that working and communicating with an awareness of a shared human condition, and an acceptance of the messiness of the social-environmental policy context, enables us to consciously choose our roles as a means of facilitating effective communication and providing policy-relevant science.

\section{Roles and the human condition}

"Play your part in the comedy, but don't identify yourself with your role!" (Wu Wei, [1960] 2004)

We live in a world faced with the challenge of the continued survival of the human species in the face of unparalleled natural resource degradation. Technological solutions proffered appear piecemeal, disjointed and inadequate for the scale of the problem. As humans, we depend heavily on nature for our physical, emotional and spiritual sustenance - we are systems living within systems, open and interconnected. We function in the world through the roles we play and the masks we wear. These roles and masks facilitate our functioning in the world in one sense, but equally they can inhibit us if we identify with them to the extent that we forget that underneath, we are all connected by a common human identity. When we live unsustainably we live as if the world we live in is limitless. Our masks, which limit us, equip us to play our role in a world which is a limited system in terms of resources. But we need the ability to use our 
masks wisely, the ability to lift our masks so that we don't become blinkered by them. Ironically, we have become blinkered to such an extent that we live as if we are limited beings in a world of limitless resources.

Scientific inquiry into roles is not a new endeavour. Role theory has been around since the 1930s (see Mead, 1934) and has been used since then in many different fields such as sociology, psychology, anthropology (Biddle, 1986). While we draw on the concept of roles in this paper, we do not consider that our discussion of roles in this paper falls within the bounds of role theory because we feel that this would limit rather than help our contribution.

This paper operates on two levels. On the one hand we use the concept of roles (in the sense of masks) in an innovative way to provide insight into the social-environmental policy-making process in the overall context of the workings of human nature. In addition, because we want to avoid a dualistic discussion of humans as separate from, and needing to be reconnected with, nature, our focus in this paper is on human nature rather than on humans and nature or on humans in nature. We draw from literature in various fields (e.g. psychology, philosophy, ecology) in our discussion of this topic, the distinctive nature of this work being its simultaneously broad and deep interdisciplinary and transdisciplinary reflection on human nature in the social-environmental policy-making context.

On the other hand, the backdrop to this paper is a sense of the potential we have to drop our masks and to tune into the limitless potential of human nature as a whole, and to bring the wisdom of that limitless potential and perspective to inform how we live in a world of limited resources.

While the style of this paper is somewhat unconventional, we feel that this is in keeping with the overall message of the paper which is urging scientists to recognise, and not be limited by, their defined roles. For example, we use metaphors, philosophical discussions and quotations to introduce the different sections. The literature cited includes such diverse works as those of a Zen Buddhist, a poet, a mediator and a philosopher, in addition to the more traditional academic literature. Thus there is potential for the reader to experience, while reading the paper, what the content of the paper is discussing - allowing and bringing a more complex human language into science.

In what follows we explore the idea that consciously dropping beneath our roles and connecting on the shared (yet infinitely varied) level of "human beingness" facilitates the creation of more complex and realistic channels of communication. We consider the limited perspectives which result from the roles we play in order to function in the world, as a stepping stone towards broadening such perspectives. In particular, as our personal experience of the issues explored in this paper has been through our roles as working scientists, we grapple with the question of how scientists can function as scientists while acknowledging that scientists are human beings with values and views. 
We use the discussion of roles as a springboard into a deeper analysis of how tangled webs of communication may be navigated to allow for a more effective and fluid social-environmental policy-making process. Although this article often discusses the broader area of socialenvironmental policy making, we draw from our experiences in the more specific area of ocean and coastal management and as such use terms social-environmental policy interchangeably with ocean and coastal policy. We discuss certain roles individuals may have in the process and what this means in the context of scientific inquiry informing policy making. In so doing, we necessarily make some sweeping generalisations about various groups of people (scientists, policy makers) and about individuals who may inhabit (from time to time or at all times) these groups. These generalisations are just that - they are unlikely to hold true at the level of an individual or a group. However, they are a necessary first step towards raising the awareness of:

- The scientist - as to the role he/or she consciously or unconsciously chooses to play in "doing" and communicating science.

- The policy maker - as to the complexity of the "scientific" approach as underpinned by a variety of human values and scientific roles and as to policy makers' understanding of the meaning of "objective" science.

A recently completed EU-funded multi-disciplinary project on integrating science and policy in the context of coastal management (SPICOSA, FP6) aimed to develop a methodology for science and policy integration and test it on a number of coastal study site areas (see Tett et al., 2011). An integral component of the methodology was a systems model, which every study site needed to develop to address a policy problem relevant to the site. The intention was to design a suite of systems models and develop them through dialogue with different policy makers in each study site, with a view to producing models which could be used by policy makers as a decision-making tool in planning and managing the coastal zone. In some study sites, the relatively clear-cut and more removed world of the modellers had difficulty engaging with the inevitably complex and particular nature of the human issues that the policy makers were grappling with on the ground. For example, how can a simple systems model tackle the policy problem of how to deliver marine spatial planning, given the multitude of interested parties involved in a marine planning process, each of which has their own set of goals, interests, and positions about their use of 'their' marine environment? The authors were involved in a study site based in the Firth of Clyde in Scotland. As the problem identified by policy makers as relevant - the delivery of marine spatial planning - was too complex to model, this study site ultimately focussed on, and successfully modelled interactions between, a mussel farm and a marina in one sea loch (Loch Fyne) in the Firth of Clyde (Tett et al., submitted for publication). However, the fitting of a policy problem to a method (i.e. a systems model) rather than the other way around meant that the policy problem ultimately had little relevance on the ground. As social scientists, we began to reflect on the grey area which separates the world of science from the policy world and to ask ourselves what was it that had impeded us from providing science that could play a meaningful role in the ocean and coastal policy-making process. Our reflections forced us to come out of the arenas of science and policy making and to start at the more basic and shared level of the human being. 


\subsection{The masks we wear}

"Your persona, beliefs and role are in reality a technique or strategy for getting through the daily routine."(O'Donohue, 1999, p. 137)

As we adopted an introspective perspective in reflecting on our experiences of the ocean and coastal policy-making process, a diagram (Fig. 1) emerged which shows three distinct yet mutually connected layers of an individual human being or a group in the context of socialenvironmental policy making.

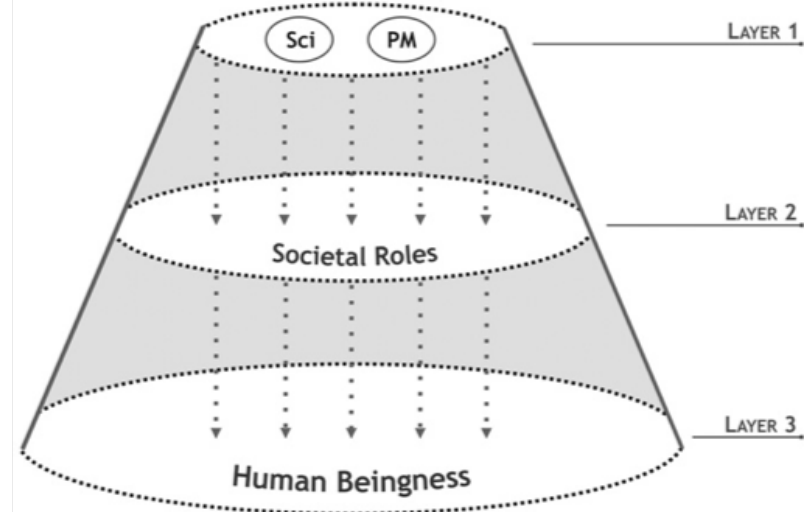

Figure 1. Roles and permeable layers of "beingness". (Sci = Scientist; PM = Policy Maker).

Layer 1 is often the most visible one. It is a role - of a scientist or policy maker - that an individual (or a group) plays and gets played at in communication with others. As such, it is in turn a role that one is assigned by the other actors in the social-environmental policy-making process. Often, however, we are not only stuck in this role (consciously or unconsciously) but also identify with our role as the only ingredient that can be brought to the table in the policymaking process. This prevents us from seeing that there are other layers of ourselves that we need to connect with as we communicate with others. Awareness that we are playing a role brings permeability to the dividing line (which is illusory anyway) leading to the next layer of our being (layer 2 ).

Within layer 2 we still have a role that we play, but it is set in the broader context of society. ${ }^{2}$ Even when we function as a scientist or policy maker, we are still a part of society and it is easy to think of situations in which we move beyond the layer 1 mask to connect with others at this deeper level (for example when we inquire about each other's children). Roles we play within this layer (e.g. as father, mother, friend, sister, brother, man, woman) appear to be a fundamental part of our identity but in actual fact they are still roles that we are playing. Awareness of this means that we add permeability to the next barrier which allows us to permeate to the common connecting level of our "human beingness" (layer 3 ).

${ }^{2}$ By society we mean the totality of social relationships among humans, drawing from its Latin root "societas" meaning fellowship. 
Layer 3 is the level where we are all connected on the common ground of a shared humanity. Yet this layer is far from homogenous, as within this level, each of us is a human being with our own unique set of values and perceptions, which we necessarily (and often times unconsciously) bring with us to the policy-making process. As Irish poet, philosopher and scholar O'Donohue (1999) puts it: "No-one else can see the world the way that you see it. Noone else can feel your life the way that you feel it. Thus it is impossible to ever compare two people with each other because each stands on such different ground" (p. 155). Despite the uniqueness of each human being on this level, in our view it is permeated by the underlying limitless and unified potential of human nature, which is what is providing the unifying connection within the differences.

Functioning through our roles makes it easier for us to map the world, as roles simplify (and therefore necessarily limit) our perspective. Moreover, we are much more vulnerable (and complex) at a "human" level so that awareness of this underlying human layer is not always easy to achieve. Roles cannot usually be relinquished on demand since we tend to identify with our roles. The dropping of a role, whether it is a scientist or policy maker, man or woman, and the consequent dropping into our underlying "humanness", is generally something that happens involuntarily but can also be nurtured into being, offering us glimpses of a different (and, we believe, fuller) way of seeing. As such, what we are advocating here is an awareness of a "multiple existence" through the roles we play out, rather than a relinquishment of such roles. In a sense, we are calling for recognition of the complexity of the self within, which may be seen as reflected by the myriad of roles we adopt to function in the world without.

Self-awareness is not in itself sufficient to unravel the entangled webs of communication that we create with others. What is needed is a step further towards a relational awareness - i.e. how we, through our adopted roles, relate to others, and how they relate to us.

\section{Disconnected perspectives and webs of connection}

"People create their lives within a web of connection to others. The cast of characters in a life and the nuances of interconnection provide the richness, the intricacy, the abrasion, and much of the interest in living. Life unfolds as a kaleidoscope of relationships, with varying pieces in shifting arrangements." (Josselson, 1996, p. 1)

The small island of Barra in the Outer Hebrides lies off the northwest coast of Scotland. Barra has a resident population of 1078 (1172 including Vatersay) and an area of $60 \mathrm{~km}^{2}$ (23 square miles). A conflict over Scottish Natural Heritage's (SNH) proposal to designate the Sound of Barra as a marine Special Area of Conservation (mSAC) has been ongoing since 2000. Since 2008, $\mathrm{SNH}^{4}$ have proposed the designation of an additional mSAC in the waters east of Mingulay. The situation has been portrayed in black and white terms to date, with SNH proposing the designation of two inshore mSACs to protectsandbanks, ${ }^{5}$ seals and a cold water coral reef (Lophelia pertusa), and the local community resisting the imposition of the mSACs due to fears that the EU designations will impose limitations on development, planning and change of the designated (and surrounding) areas and concerns that they could impede existing 
uses (such as fishing).The formation in 2008 of the local action group SHAMED (Southern Hebrides Against Marine Environmental Designations) is evidence of the increasing polarisation of the conflict. The Chairman of SHAMED has identified the social and economic wellbeing of the Barra community as being linked to local control over the use and care of Barra's natural resources.

${ }^{3}$ General Register Office for Scotland (28 November 2003). Occasional Paper No. 10. Scotland's Census 2001 Statistics for Inhabited Islands. http://www.gro-scotland.gov.uk/census/censushm/occpapers/occasionalpaper-10/index.html (accessed 13.02.12.).

${ }^{4}$ Scottish Natural Heritage (SNH) advises the Scottish Government on natural heritage issues and provides a natural heritage input to the development of Scottish Government policies and guidance.

${ }^{5}$ Specifically maerl beds - maerl is a seaweed with a hard skeleton.

When one of the authors carried out six weeks of fieldwork in Barra during September and October 2011, she discovered that at least two very different, and disconnected, understandings of the meaning of 'conservation' exist in this conflict. The intention of conservation bodies to protect the Sound of Barra, and the process which has been carried out in administering the requirements of the European Habitats Directive(92/43/EEC) in the Sound of Barra (discussed further in Section 4), sends a 'hands-off' and 'keep-out' message to the local community. In contrast, the local sense of conservation is one of 'live with' and 'use/develop wisely', which is underpinned by a sense of thrift and ingenuity essential to human survival in a remote coastal community. It is hardly surprising that the process of designation of the Sound of Barra should have engendered the hostile response it has received from the community when it is clearly stated by SNH that regulating authorities are responsible for managing SACs in consultation with $\mathrm{SNH}$ (SNH, undated, p.6). This serves to increase the sense of foreboding amongst the local community that a 'hands-off' conservation model will prevail. This fear cannot be resolved by reassurances emanating from the regulating authorities or government advisors as the 'consultation' process for the Sound of Barra (discussed in Section 4) has served to increase the sense of suspicion and distrust around the designation process. This suspicion and distrust is exacerbated by the lack of transparency around this process.

Like the polarisation of the conflict, the two different understandings of the meaning of 'conservation' appear to be irreconcilable. At the same time, both could be understood as different, but complementary, perspectives. As Nietzsche (1887) observes, " $[\mathrm{t}]$ here is only a perspective seeing, only a perspective 'knowing'; the more affects we allow to speak about a thing, the more eyes, various eyes we are able to use for the same thing, the more complete will be our concept of the thing..." (p. 12). It is, however, very difficult to accept the interconnectedness of different 'perspective seeings' when one perspective appears to be the polar opposite of another.

The word "interbeing" was coined by a Vietnamese Buddhist Zen master Thich Nhat Hanh in the second half of the 20th century. The idea of interbeing, however, has been around for millennia. We find the understanding of the interconnectedness of all beings and all things in the world in ancient spiritual traditions of Taoism, Buddhism, and Hinduism, mystical teachings 
of Judaism, Islam, and Christianity, and among traditions, cultures, and practices of the currentday indigenous peoples (Macy and Brown, 1998). We see it also in poetical musings and artistic renderings, and throughout the history of philosophical thought (see, for example, Dewey, [1926] 1984). More recently, we see the idea of interbeing filtering into various domains of scientific thought and practice, from psychology ${ }^{6}$ and ecosystem ecology ${ }^{7}$ to systems thinking and sustainability studies, ${ }^{8}$ to name a few. At a practical level, we may consider the rise in popularity of the 3600 feedback, by which colleagues at different levels of management (subordinates, peers, managers) as well as receivers of service (e.g. customers) give feedback to an individual about both her work performance and behaviour (London and Beatty, 1993). The evaluated individual through her actions weaves a web of connection around herself and is in turn woven within it by those she comes in contact with and by those whose work depends on her performance.

${ }^{6}$ See Josselson (1996), and Misztal (1996).

${ }^{7}$ See Odum (1994), and Holling (1973).

${ }^{8}$ See von Bertalanffy (1969), Gunderson and Holling (2001), Berkes and Folke (1998).

The intention here is not to survey the domain of interbeing across disciplines, religions, arts, or philosophical thought. It is rather to point out that the idea of interbeing can be found in many corners of our society, past and present, and to suggest that there is no need to keep these realms of spiritual/artistic/philosophical and scientific inquiries separate. Rather, they too need to merge together in order for us to tap into the essence of their teachings and to explore what all this means for the realities of modern life.

Speaking from the field of psychology, Josselson (1996) notes that finding a language for this realm of human interconnection is not easy, as "[t]his is a different sort of place, this interpersonal sphere. It exists in the realm of the subjective and affective, the symbolic and the transcendent. Much of what really matters here is beyond words" (p. 15).

A striking modern example of humans seeking connection with other humans is how quickly and all-pervasively e-communication has been accepted around the world. This expansive web of connection may be a modern day allegory for the interconnectedness of human beings. And yet, while e-communication certainly reflects a desire for human community, what it creates may be rather "community without communion" and reinforcement of various roles (e.g. "facebook friend"). Perhaps this is so because what really matters is between words: "Real conversation is not a construct of the solitary ego; it creates community. So much of our modern talk is like a spider manically weaving a web of language outside himself. Our parallel monologues with their staccato stutter only reinforce our isolation. There is so little patience for the silence from which words emerge or for the silence that is between words and within them" (O'Donohue 1999, p. 144). There was little space for silence at the Sound of Barra Consultation Meeting discussed in Section 4 below.

3. Scientific roles - what lies beneath

"It is difficult to see anything clearly until we see ourselves, until we see who it is that is seeing." (Cloke, 2001, p. 47) 
These ponderings and reflections become more meaningful to us if we are willing to apply them to ourselves and look at, and behind, the masks we wear as scientists. It may sound obvious to state that all scientists are not the same. However, this statement is not limited to the equally obvious fact that all scientists do not think in the same way. Less obvious is the recognition (both by scientists themselves and by the non-scientific community) that "...scientists are both human beings and citizens, and as such have values and views" (Pielke, 2007, p. 147). An example of how easy it is to forget this is the backlash that erupted against the University of East Anglia (UEA) in November 2009 in the wake of leaked emails around climate change science. This is not to deny the responsibility held by a scientist in his or her role as a scientist. However, it was remarkable that the coverage of the entire episode focused on the scientists in their role as scientists, with no reference to them as human beings with values and views. It was only several months after the event, in an interview with Professor Phil Jones, the head of the Climactic Research Unit at UEA, that a human element crept in with the revelation that the intensity of the backlash had pushed this man to the verge of suicide (Laing, 2010). The same article quoted the Professor as saying: "I am just a scientist. I have no training in PR or dealing with crises" - a telling example of identification with a role. An even more dramatic example of identification with a role is that of Dr David Kelly, a British scientist and expert on biological warfare employed by the British Ministry of Defence. Dr Kelly (allegedly) committed suicide in 2003 in the midst of a public controversy over the evidence for the existence of weapons of mass destruction in Iraq.

Pielke (2007) identifies 4 idealised roles that scientists can choose to play in relation to policy and politics:

- Pure scientist ${ }^{9}$ : focuses on research with no consideration for its use or utility; doesn't seek to compel a particular decision outcome;

- Science arbiter: answers factual/positive (but not normative) questions for the decisionmaker; doesn't seek to compel a particular decision outcome;

- Issue advocate: focuses on implications of research for a particular political agenda and aligns with a group seeking to advance its interests through policy and politics; seeks to compel a particular decision;

- Honest broker of policy alternatives: clarifies and sometimes expands scope of choices available to decision-makers, and seeks to integrate scientific knowledge with stakeholder concerns in the form of alternative possible courses of action; seeks to enable freedom of choice by a decision-maker.

Thus the role of scientist within the social-environmental policy-making process can be further sub-divided into roles within a role. ${ }^{10}$ Another layer of complexity is the importance of consciously choosing the role. Awareness by scientists of the role we play in providing science to policy makers and society has interesting ramifications for the hallowed view of science as objective fact. This is because by becoming aware that we are choosing to play a role as scientists, we are acknowledging that through this role, we can only ever see a particular piece of the puzzle. 
9 "In the public mind there is no such thing as 'pure' science." (Taylor, 2007, p. 163)

${ }^{10}$ We consider Pielke's (2007) suggested division of roles as useful for the purposes of discussion in this paper. We are not, however, suggesting that this is the only way in which the roles of scientists could be expressed.

\subsection{The illusion of objective science in the social-environmental policy world}

"...thus far the growth of disciplinary scientific methods and bodies of knowledge results in an increasing disunity that translates into a multitude of different yet equally legitimate scientific lenses for understanding and interpreting nature." (Sarewitz, 2004, p. 390)

The idea of science being objective is what gives it value to both policy makers in terms of being able to rely on it and to the public in terms of it being an independent source of information that is (supposedly) untainted by political views. But this very objectivity is in a sense setting up a barrier in the form of an unattainable and illusory ideal because it denies the underlying humanness of the scientist, which is necessarily subjective as it is, in Nietzsche's words, only "a perspective seeing". Dewey ([1931] 1989) takes the view that "[b]ias for impartiality is as much a bias as is partisan prejudice, although it is a radically different quality of bias. To be "objective" in thinking is to have a certain sort of selective interest operative. One can only see from a certain standpoint, but this fact does not make all standpoints of equal value" (p. 14).

Yet it is undeniable that science provides us with a critically tested body of information which we rely upon, as scientists and policy makers, because of the rigorous and replicable methods through which this body of information has been produced. Valid science rests on an established process for inquiry, logic, and validation (Lubchenco, 1998).

A distinction therefore must be drawn: between the objectivity of scientific methods and their application on the one hand, and the interpretation of the results produced on the other, which are necessarily influenced by individual perceptions (even if there are many such perceptions in agreement on an interpretation) - such interpretations reflect "a perspective seeing".

With this distinction in mind, it is unhelpful to ascribe the label of "objective" to science on an indiscriminate basis because this label distances the recipients of the science from the (many and varying) human qualities of the scientist(s) providing the science. It thus perpetuates the illusion that the scientist as scientist can be disconnected from the scientist as human being living in a value-laden society playing out the role of scientist. It also raises the question of whether science reinforces the human tendency to deny our own fallibility. There are therefore (at least) three layers of complexity which scientists, policy makers and society in general need to be aware of:

- Distinguishing objective results ${ }^{11}$ from subjective interpretations and conclusions;

- The role played by a scientist in providing and communicating science; and

- Our interconnecting "human beingness". 
${ }^{11}$ We are aware that the objectivity we refer to here is not always (if ever) purely objective - for example, experiments are designed to address a particular issue, so that results may be inadvertently skewed by purposeful design.

If we are aware of the subjectivity that underlies science through the fact that it has been provided by humans, in this awareness we are acknowledging the "human beingness" of scientists, which connects with the "human beingness" of non- scientists, lying beneath the outer roles being played by the respective parties. On the other hand, allowing science to be on a pedestal may be necessary for both scientists and non-scientists to accept, and rely on, the certainty it provides. Acknowledging that science is, ultimately, a product of a human being (and therefore fallible) could irreparably damage the role that science itself plays in society. In a sense, therefore, science too masquerades behind a role: there is the role of science on a pedestal providing certainty and an independent source of information, yet at the same time, below that role or mask (which is necessary for science to function in and be useful to society) science is as fluid, flexible and ever-changing as human nature, precisely because it is created by the human mind.

\subsection{Tangled webs of communication in the social-environmental policy world}

The illusion of objectivity perpetuated by the policy world alongside the roles played by scientists, often unwittingly and beyond the awareness of policy makers, creates fertile ground for communication entanglement. There is a lot of discussion these days about the importance of bridging the communication gap between scientists and policy makers, and on how scientists can better communicate the results of science to those responsible for decision-making. We prefer to talk about navigating tangled webs of communication rather than bridging communication gaps as we feel that this better reflects the communication chaos that often results as different ways of seeing the world collide with each other. Such collisions result in incoherent and often unfathomable entanglements rather than void-like gaps.

The SPICOSA project (referred to in Section 1 above) illustrates an example of communication entanglement. One of the difficulties encountered was that the policy problem was supposed to be identified before the methodology was fully developed. As a result, when a policy problem was identified as relevant by the policy makers consulted (e.g. the implications of increased leisure and tourist use of the Firth of Clyde) which then turned out to be too complicated to be addressed using systems modelling (when the methodology was developed), it had to be discarded and replaced by a less complex policy problem to fit within the model. This process was frustrating for the social scientists involved in the Firth of Clyde case-study as the definition of the policy problem to be engaged with moved further and further away from the realities on the ground where the policy makers were struggling to find a way to deliver policies relevant to a complex human world.

This example illustrates an entanglement between a "pure scientist", in the SPICOSA case embodied by those developing the methodology, and either a "science arbiter" or an "honest broker" represented by social and policy scientists working (or attempting to work) with policy 
makers and interested parties at study sites. The entanglement further led to the development of the model in an ivory tower: as the "science arbiter" and "honest broker" scientists remained locked within the prescribed methodology of the "pure scientist", they could not truly engage with policy makers, and society was completely left out of the picture. This further illustrates how remaining firmly in our roles as scientists serves no purpose in achieving connection between policy makers, society, and ourselves.

Were the Firth of Clyde study to be repeated, it would, for example, better engage policy makers and society and involve them from the beginning in the conceptualisation of the model as well as in deliberating its results to ensure the relevance of the study to the social environment (Tett et al., submitted for publication). This is also a good example of how difficult we find it as scientists (operating within the clearly defined roles and masks of science) to deal with the "wickedness" of policy problems. "Wicked" problems are difficult to define and delineate from other problems, they have no right or wrong solution which can be determined scientifically, it is not clear when they are solved, and they need to be dealt with by a collective process which is experiential, interactive and deliberative (Jentoft and Chuenpagdee, 2009). Many scientists and policy makers prefer solutions which reflect a shallow surface consensus rather than more complex approaches which require value judgements and acceptance of the fact that there are "losers" and that these are human beings with feelings that they will express.

\section{The space between scientists and the non-scientific community}

"Now one rather annoying thing about scholars is that they are always using Big Words that some of us can't understand... and one sometimes gets the impression that those intimidating words are there to keep us from understanding. That way, the scholars can appear Superior, and will not likely be suspected of Not Knowing Something. After all, from the scholarly point of view, it's practically a crime not to know everything.

But sometimes the knowledge of the scholar is a bit hard to understand because it doesn't seem to match up with our own experience of things. In other words, Knowledge and Experience do not necessarily speak the same language. But isn't the knowledge that comes from experience more valuable than knowledge that doesn't? It seems fairly obvious to some of us that a lot of scholars need to go outside and sniff around - walk through the grass, talk to the animals. That sort of thing." (Hoff, 1989, p. 28-29)

Much progress has been made over the past two decades on communicating science to policy makers and the public. In 1985 the British "Bodmer Report" (The Royal Society, 1985) called for scientists to "learn to communicate with the public, be willing to do so, and indeed consider it their duty to do so. All scientists need...to learn...how to explain science simply, without jargon and without being condescending"(p. 6). However, surveys suggested that little had been achieved in improving the public's scientific literacy in the decade which followed (Miller, 2001). Fifteen years later, another report, "Science and Society" (House of Lords, 2000) cleared the way for "full, frank, and publicly inclusive dialogue, discussion, and debate about science and its implications for individuals and society" (Miller, 2001, p. 119). In the last decade, 
Schäfer (2009) points to a shift away from the "public understanding of science" deficit model towards a model of public engagement with science, highlighting the need for dialogue with the public rather than one-way information provision. Thus, "[s]cience communication is no longer seen as merely a vehicle to increase acceptance amongst the public by simply transporting or translating science for the audience" (Schäfer, 2009, p. 476). This focus on engaging the public in science is not limited to Britain. Indeed Taylor (2007) observes that "[p]ublic engagement in scientific research has gone viral...It has also gone global" (p. 163). In the US, the importance of communicating science has been highlighted by Lubchenco (1998). Ward (2008) describes a series of communication efforts between scientists and journalists over the past decade. Examples of successful initiatives in the US include the Partnership for Interdisciplinary Studies of Coastal Oceans (PISCO) ${ }^{12}$ and the Aldo Leopold Leadership Training Program. ${ }^{13}$ On a global scale, the Intergovernmental Panel on Climate Change (IPCC) provides a good example of scientific efforts to communicate the complex issue of climate change. ${ }^{14}$

12 http://www.piscoweb.org/.

${ }^{13}$ http://leopoldleadership.stanford.edu/.

${ }^{14}$ http://www.ipcc.ch/

While the more traditional "public understanding of science" deficit model of science communication still exists (see Davies, 2008), progress has undeniably been made in developing strategies for public engagement in science and a more nuanced understanding of what effective communication and engagement involves is beginning to come through. Davies (2008) observes that it is not science as an establishment that engages with society, it is individuals, and that "it is therefore the practices of individuals which will frame and shape the communication process" (p. 414). She points to evidence that individual scientists' contact with the public increases the use of more complex and more realistic models of communication as this helps scientists have a more complex and realistic understanding of the "public" and to move away from the "public understanding of science" deficit model of communication which is a one-way system that assumes the public don't know and need to be informed. We see Davies' observations as evidence of the scientist and the public actually engaging in discourse through a multitude of roles, and not just via one-dimensional masks of "scientist" informing "layperson". We take the view that when people are simultaneously engaging with each other through a multitude of roles, the complexity of the human condition and how we function is being acknowledged and reflected, and this in turn creates the more complex and realistic models of communication which Davies (2008) talks about.

Our recent experience, however, indicates that the "public understanding of science" deficit model of science communication is being used in practice but under the guise of public engagement in science. For example, while the terminology of public engagement in science is being used liberally, 'stakeholder consultations' often consist of 'informing' rather than 'consulting with' the public. The creation of a Natura 2000 network of Special Areas of Conservation (SACs) under the European Habitats Directive exacerbates this problem as it does not permit social or economic factors to be taken into account in the designation of a SAC. The 
public must therefore contest the science if they wish to challenge the designation of a SAC in a particular area.

The ongoing dispute around the proposed designation of two marine SACs off the small Outer Hebridean island of Barra has resulted in public alienation from, rather than engagement with, science (the science being represented by Scottish Natural Heritage (SNH), the government body responsible for advising the Scottish Government ${ }^{15}$ on proposed SACs). On 3 October 2011, one of the authors attended a 'Consultation Meeting' held by SNH to consult the Barra islanders on the proposed Sound of Barra marine SAC. The agenda for the meeting involved five different presentations (with a request for no questions during presentations) before any dialogue (in the form of a questions and answers session) was introduced. The tension and frustration of the eighty (approximately) islanders attending the meeting was palpable throughout the government presentations. By the time the question and answer session took place, people in the audience were at boiling point, and very little real communication, if any, took place. There was little scope for moving beyond identification with roles to connecting at the shared level of 'human beingness' as the SAC process did not permit SNH to take into account the 'human' element (social and economic considerations) in making its case to the Scottish government for proposing the Sound of Barra as a marine SAC. The format of the meeting, which involved SNH and Marine Scotland ${ }^{16}$ providing information to the local community through a series of non-interactive presentations, exacerbated the situation. While space was provided for a local speaker to present the local perspective, this presentation adopted the same lecturing style as the government presentations so that even the local representative perpetuated the 'no dialogue' dynamic. It was ironic that, 3 days later, the UK National Health Service (NHS) for the Western Isles and the Scottish Health Council ran an "Engagement Methods 'drop-in' session" on Barra under the theme of "How to Engage Well" (with communities) with information on a wide range of facilitation methods and engagement techniques which could have transformed the Sound of Barra 'Consultation Meeting'.

${ }^{15}$ In Scotland, government policy is to consult on social and economic factors even though these cannot be taken into account in the making of the decision as to whether to propose a particular area to the European Commission as a SAC.

${ }^{16}$ Marine Scotland is a Scottish Government directorate responsible for the integrated management of Scotland's seas.

\subsection{Some practical reflections}

If communicating through a variety of roles enhances the flow of communication and creates better communication models, what then could happen if we were knowingly (rather than unconsciously) able to also communicate on the level of human beingness, which is the level on which we really connect? In practical terms, how can we shift our perspectives so that we can navigate the otherwise invisible labyrinthine webs that we create between us?

\subsubsection{Accepting, and working with, the messiness of it all}


Communicating science to policy makers and to the public is undeniably a messy business because it calls on us as scientists to merge with the non-scientific world and to function outside the carefully constructed masks and roles within which science is carried out. It also calls on policy makers to become aware of the subjectivity that underlies science, and how the objectivity which policy makers value so highly is denying the underlying humanness of the scientist and, in turn, reinforcing the human tendency to deny our own fallibility. But if we don't acknowledge and accept the messiness of it all, we are simply burying our heads in the sand with no hope of discerning a way through the labyrinth of communication entanglements. If we acknowledge at the outset the messiness of it all, then we are in a more honest position to choose, with awareness, the role we wish to play.

\subsubsection{Consciously choosing roles}

We can consciously choose the role we wish to play as a scientist and make this clear to policy makers when asked to advise them either through scientists explicitly informing policy makers (or policy makers explicitly asking the question) of what role a scientist has played in providing the science requested. For example, a recent commercial tender on the management of marine protected areas expressly requested an "advocacy piece". This was a clear call for scientists to play the role of "issue advocate". In discussing the tender, none of the scientists on the team felt comfortable playing such a role, the social scientists preferring to choose the roles of "honest broker" and the natural scientists the role of "science arbiter". When we tendered for the work (which we were subsequently awarded), we made clear that we would not be able to provide an "advocacy piece" as requested but that we would be happy to carry out the work in the roles described.

Admittedly, trying to be explicit about the roles of scientists could quickly become very complicated in larger projects where hundreds of interdisciplinary scientists are working together. When faced with such levels of entanglement, a short survey at the end of a project could give some idea to the recipients of the science as to what roles the scientists played in providing science to policy makers. Of course, this all assumes a level of self-awareness and honesty on the part of scientists which is where another practical stumbling block appears: how many of us are going to admit to being aware of being "issue advocates" if we feel that this is not something we should be? Despite such drawbacks, we feel that explicitly asking the question of ourselves as scientists would start to bring awareness to the roles we play, and that is the next step.

\subsubsection{Bringing it all back to the human level}

We can be aware that we live a "multiple existence" through the masks we wear and the roles we play out, and thus be open to the possibility of seeing behind those masks and roles by dropping into the connecting level of our underlying humanness so that our multiple existence can translate into Nietzsche's (1887) "various eyes we are able to use for the same thing" ( $p$. 12). As mentioned earlier, this dropping into our underlying "human beingness" usually 
happens involuntarily, but can also be nurtured into being, simply by reminding ourselves on an ongoing basis of our underlying interconnectedness at the shared level of humanity.

\section{Conclusion}

The SPICOSA project revealed that the more firmly we adopted the role of 'scientist', the more removed from the social reality the research became. The ongoing marine SAC conflict in Barra illustrates the disillusionment and breakdown in communication which results from an inability to see (and therefore communicate) beyond roles (of 'government advisor' or 'persecuted local community'). Both case studies provide examples of how roles can (usually unconsciously) be used in a 'blocking' rather than 'facilitating' manner.

As individuals, we can never have a complete picture, and depending on which mask we wear, some facts may appear important and compelling and others trivial to one person, while the exact opposite may be the case for another individual. While awareness and acceptance of the limitations of our perceptions demands a certain humility, it (paradoxically) opens up the possibility of broadening our perspectives. When we become aware of this in ourselves, we also realise that many other human beings have the illusion that their perspective is the "right" one and may not be able to see beyond that. Regardless of the awareness of others, if we are aware that we all only ever have a part of the whole picture, then our perspective on the perspectives of others shifts - so that their perspectives become illuminating threads which shed light on the (fuller) picture rather than obstacles obscuring it.

On a final note, we are aware that scientists and policy makers are struggling with the complex task of dealing with the social, economic and ecological parts of an ecosystem in an integrated manner. We believe that allowing and bringing a more complex human language into science is essential to dealing with this difficult and complex task.

\section{Acknowledgements}

The authors are grateful to Professor Laurence Mee and an anonymous reviewer for insightful comments on earlier drafts of this paper and to Lovro Valcic for his technical assistance with Fig. 1. The research on Barra received funding from the National Trust for Scotland and from the MASTS pooling initiative (The Marine Alliance for Science and Technology for Scotland) and their support is gratefully acknowledged. MASTS is funded by the Scottish Funding Council and contributing institutions. The SPICOSA project was funded by the EU's Sixth Framework Programme.

\section{References}

Berkes, F., Folke, C. (Eds.), 1998. Linking Social and Ecological Systems: Management Practices and Social Mechanisms for Building Resilience. Cambridge University Press, Cambridge.

von Bertalanffy, L., 1969. General Systems Theory: Foundations, Development, Applications, revised ed. George Braziller, Inc., New York. 
Biddle, B.J., 1986. Recent development in role theory. Annual Review of Sociology 12, 67-92.

Cloke, K., 2001. Mediating Dangerously: The Frontiers of Conflict Resolution. Jossey-Bass, San Francisco.

Davies, S.R., 2008. Constructing communication - talking to scientists about talking to the public. Science Communication 29 (4), 413-434.

Dewey, J., [1926] 1984. The public and its problems. In: Boydston, J.A. (Ed.), The Later Works of Dewey 1935-1937. Southern Illinois University Press, Carbondale, vol. 2, 235-372.

Dewey, J., [1931] 1989. Context and thought. In: Boydston, J.A. (Ed.), The Later Works of Dewey 1931-1932. Southern Illinois University Press, Carbondale, vol. 6, 3-21.

Gunderson, L.H., Holling, C.S. (Eds.), 2001. Panarchy: Understanding Transformations in Human and Natural Systems. Island Press, Washington, DC.

Hoff, B., 1989. The Tao of Pooh...in Which The Way is revealed by the Bear of Little Brain. Mandarin Paperbacks, London.

Holling, C.S., 1973. Resilience and stability of ecological systems. Annual Review of Ecology and Systematics 4 (1), 1-23.

House of Lords, 2000. Science and Society. Her Majesty's Stationary Office, London.

Jentoft, S., Chuenpagdee, R., 2009. Fisheries and coastal governance as a wicked problem. Marine Policy 33 (4), 553-560.

Josselson, R., 1996. The Space Between Us: Exploring The Dimensions of Human Relationships. Sage Publications, Inc., London.

Laing, A., February 7 2010. 'Climategate' Professor Phil Jones 'considered suicide over email scandal'. The Telegraph. Available from:

http://www.telegraph.co.uk/earth/environment/climatechange/7180154/ClimategateProfessor-Phil-Jones-considered-suicide-over-email-scandal.html (accessed 30.06.11.).

London, M., Beatty, R.W., 1993. 360-degree feedback as a competitive advantage. Human Resource Management 32 (2-3), 353-372.

Lubchenco, J., 1998. Entering the century of the environment: a new social contract for science. Science 279 (5350), 491-497.

Macy, J., Brown, M.Y., 1998. Coming Back to Life: Practices to Reconnect Our Lives, Our World. New Society Publishers, Gabriola Island. 
Mead, G.H., 1934. Mind, Self and Society. University Chicago Press, Chicago.

Miller, S., 2001. Public understanding of science at the crossroads. Public Under-standing of Science 10 (1), 115-120.

Misztal, B.A., 1996. Trust in Modern Societies: The Search for the Bases of Social Order. Polity Press, Cambridge.

Nietzsche, F., 1887. A genealogy of morals (part III). Quotation retrieved from. http://www.philosophos.com/philosophical_connections/profile_091.html.

O’Donohue, J.,1999. AnamCara-Spiritual Wisdom from the Celtic World. Bantam Books, UK.

Odum, H.T., 1994. Ecological and General Systems: An Introduction to Systems Ecology, revised ed. University Press of Colorado, Boulder.

Pielke, R.A., 2007. The Honest Broker - Making Sense of Science in Policy and Politics. Cambridge University Press, New York.

Sarewitz, D., 2004. How science makes environmental controversies worse. Environmental Science 7 (5), 385-403.

Schäfer, M.S., 2009. From public understanding to public engagement. An empirical assessment of changes in science coverage. Science Communication 30 (4), 475-505.

$\mathrm{SNH}$, undated. Scottish Natural Heritage. Answers to some questions you may have. Available from: http://www.snh.gov.uk/protecting-scotlands-nature/protected-areas/siteconsultations/sound-of-barra/ (accessed 04.01.12.).

Taylor, P.L., 2007. Rules of engagement. Nature 450, 163-164.

Tett, P., Sandberg, A., Mette, A. (Eds.), 2011. Sustaining Coastal Zone Systems. Dunedin Academic Press, Edinburgh.

Tett, P., Valcic, B., Potts, T., Whyte, C., Culhane, F., Fernandes, T. Mussels and yachts in Loch Fyne, Scotland: a case study of the science-policy interface. Ecology and Society, submitted for publication.

The Royal Society, 1985. The Public Understanding of Science. Royal Society, London.

Ward, B., 2008. Communicating on climate change: an essential resource for journalists, scientists, and educators. Available from:

http://www.metcalfinstitute.org/Communicating_ClimateChange.htm (accessed 30.06.11.). 
Wei Wu Wei, [1960] 2004. Why Lazarus Laughed: The Essential Doctrine, Zen-Advaita-Tantra, Sentient Publications, Boulder. 